\title{
COMPARISON OF CAVITATION-EROSION RESISTANCE OF CARBURIZED AND CARBURIZED-PLUS-NITRIDED 316LN STAINLESS STEEL IN MERCURY
}

S. J. PAWEL

MAY 2007

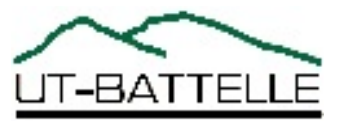




\title{
DOCUMENT AVAILABILITY
}

Reports produced after January 1, 1996, are generally available free via the U.S. Department of Energy (DOE) Information Bridge.

Web site http://www.osti.gov/bridge

Reports produced before January 1, 1996, may be purchased by members of the public from the following source.

\author{
National Technical Information Service \\ 5285 Port Royal Road \\ Springfield, VA 22161 \\ Telephone 703-605-6000 (1-800-553-6847) \\ TDD 703-487-4639 \\ Fax 703-605-6900 \\ E-mail info@ntis.fedworld.gov \\ Web site http://www.ntis.gov/support/ordernowabout.htm
}

Reports are available to DOE employees, DOE contractors, Energy Technology Data Exchange (ETDE) representatives, and International Nuclear Information System (INIS)

representatives from the following source.

Office of Scientific and Technical Information

P.O. Box 62

Oak Ridge, TN 37831

Telephone 865-576-8401

Fax 865-576-5728

E-mail reports@adonis.osti.gov

Web site http://www.osti.gov/contact.html

This report was prepared as an account of work sponsored by an agency of the United States Government. Neither the United States Government nor any agency thereof, nor any of their employees, makes any warranty, express or implied, or assumes any legal liability or responsibility for the accuracy, completeness, or usefulness of any information, apparatus, product, or process disclosed, or represents that its use would not infringe privately owned rights. Reference herein to any specific commercial product, process, or service by trade name, trademark, manufacturer, or otherwise, does not necessarily constitute or imply its endorsement, recommendation, or favoring by the United States Government or any agency thereof. The views and opinions of authors expressed herein do not necessarily state or reflect those of the United States Government or any agency thereof. 
Metals and Ceramics Division

Comparison of Cavitation-Erosion Resistance of Carburized and Carburized-Plus-Nitrided 316LN Stainless Steel in Mercury

S. J. Pawel

Date Published: May 2007

Prepared for the

U.S. Department of Energy

Spallation Neutron Source

Prepared by

OAK RIDGE NATIONAL LABORATORY

Oak Ridge, Tennessee 37831-6285

managed by

UT-Battelle, LLC

for the

U.S. DEPARTMENT OF ENERGY

under contract DE-AC05-00OR22725 



\section{CONTENTS}

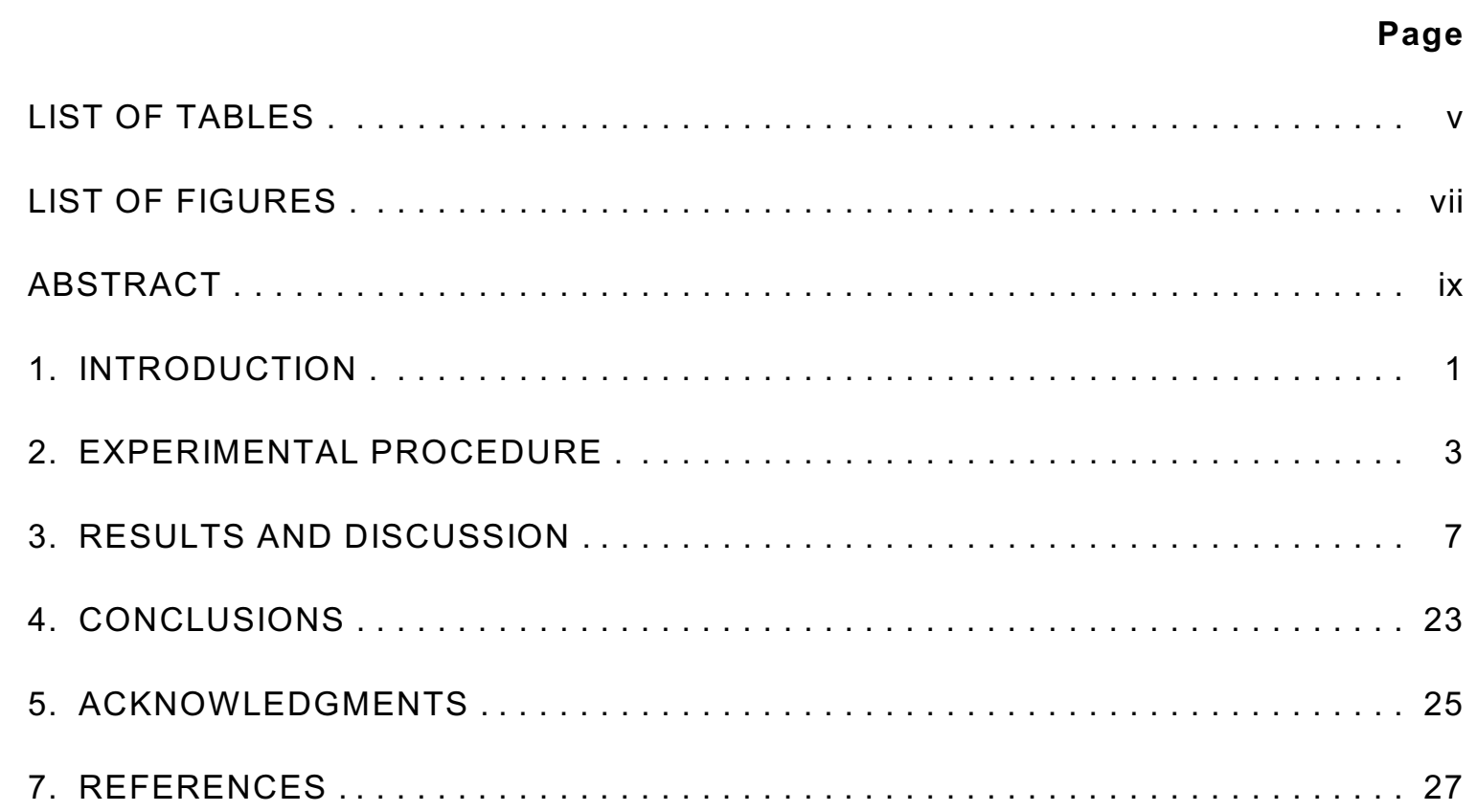





\section{LIST OF TABLES}

Table

Page

1. Composition of master heat of $316 \mathrm{LN}$ stainless steel from certified

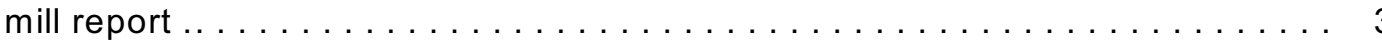

2. Average surface profile data for the $\mathrm{K}+\mathrm{N}$ layer specimens compared

to the average of all K-layer only specimens. . . . . . . . . . . . . 19 



\section{LIST OF FIGURES}

$\begin{array}{ll}\text { Figure } & \text { Page }\end{array}$

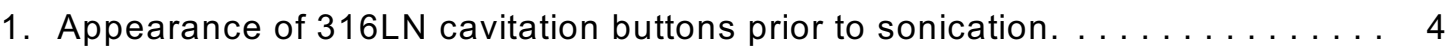

2. Weight loss as a function of sonication time in mercury for $316 \mathrm{LN}$ specimens receiving the $\mathrm{K}+\mathrm{N}$ treatment (solid data points representing

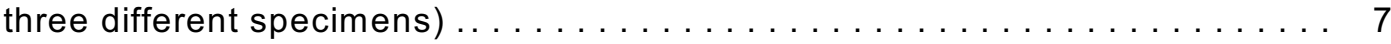

3. Representative cross-section of the side of a test button indicating the thickness and appearance of the as-treated $\mathrm{K}+\mathrm{N}$ layers $\ldots \ldots \ldots \ldots \ldots \ldots$

4. Cross-section of a threaded portion of a test button showing the same

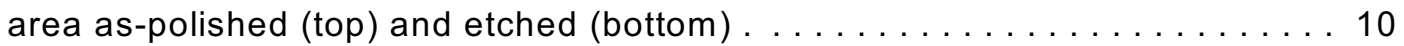

5. Cross-section of a specimen thread tip from which most of the N-layer

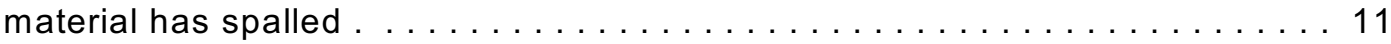

6. Cross-section of a specimen thread showing spallation of the $\mathrm{N}$-layer at the tip and curved cracks in the nearby remaining $N$-layer . . . . . . . . 12

7. Cross-section of the test face of a $\mathrm{K}+\mathrm{N}$ specimen sonicated for $3 \mathrm{~h}$ in

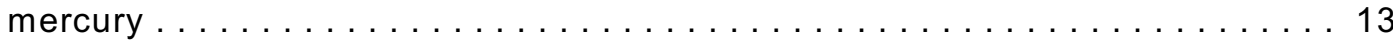

8. Cross-section of the test face of a $\mathrm{K}+\mathrm{N}$ specimen sonicated for $7.5 \mathrm{~h}$

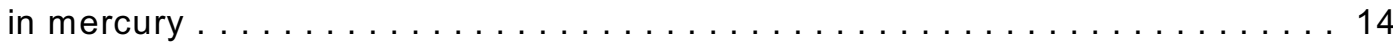

9. Cross-section of the test face of a $\mathrm{K}+\mathrm{N}$ specimen sonicated for $15 \mathrm{~h}$

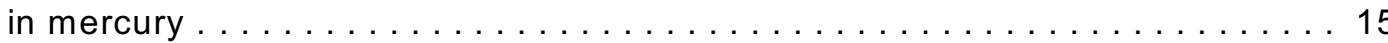

10. Cross-section of the test face of a $K+N$ specimen sonicated for $15 \mathrm{~h}$

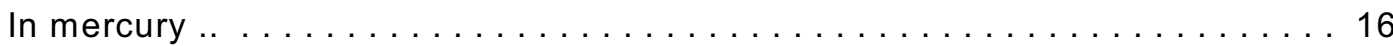

11. Remaining $\mathrm{N}$-layer thickness on the test surface as a function of sonication time in mercury at ambient temperature .. . . . . . . . . . . 17

12. Comparison of post-test surfaces of as-sonicated specimens $\ldots \ldots \ldots \ldots 21$

13. Microhardness data on $\mathrm{K}+\mathrm{N}$ layer specimens taken on cross sections

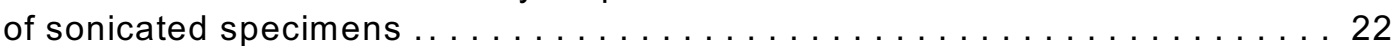





\begin{abstract}
Annealed type $316 \mathrm{LN}$ stainless steel in the (1) carburized and the (2) carburized plus nitrided conditions was evaluated for cavitation-erosion resistance in ambient temperature mercury using a vibratory horn method. The results indicated that, relative to the specimens receiving only the carburizing treatment, the specimens that received both surface treatments exhibited substantially greater weight loss, general thinning, and profile development as a function of sonication time - with all observed degradation limited to the nitrided layer. Further, the nitride layer was observed to be susceptible to extensive cracking (occasionally leading to spallation), but the cracking was never observed to penetrate into the carburized layer. These screening test results suggest there is no improvement in cavitation-erosion resistance associated with augmentation of the carburizing treatment with plasma nitriding.
\end{abstract}





\section{INTRODUCTION}

At the Oak Ridge National Laboratory's Spallation Neutron Source (SNS), a pulsed, high energy beam of protons interacts with a liquid mercury target to generate neutrons. The high energy pulses are expected, via the high localized heating rate in the target, to lead to thermal-shock induced pressure waves in the mercury. These pressure waves, after reflection from the target container surfaces, will result in negative pressure transients and cavitation in the target liquid. The energy released from the collapsing cavitation voids - typically manifested as a jetting action of liquid at high velocity - is expected to cause potential erosion and/or pitting of the adjacent containment surfaces.

One of the techniques considered for improving the cavitation-erosion resistance of the type 316/316LN stainless steel used for the target containment vessel is the use of a proprietary low temperature carburizing treatment termed Kolsterising ${ }^{\circ}$ (registered trademark of the Bodycote Company, Apeldoorn, Netherlands). The standard Kolsterising ${ }^{\circledR}$ treatment is known ${ }^{1}$ to provide substantial surface hardening without significant deleterious formation of carbides or other phases in a layer 30-35 $\mu \mathrm{m}$ deep at the surface of treated $316 / 316 \mathrm{LN}$, and the efficacy of this treatment for improvement of cavitation-erosion resistance of $316 \mathrm{LN}$ in mercury has been previously demonstrated in this laboratory. 24

At the time the Kolsterising ${ }^{\circledR}$ process was initially being evaluated for the SNS project, international collaborators with the project were investigating various forms of nitriding as a surface hardening mechanism for austenitic stainless steels such as $316 \mathrm{LN}$. Similar to Kolsterisation ${ }^{\circledR}$, nitriding the surface of annealed stainless steel also seemed to offer significant improvement in cavitation-erosion resistance. However, initial limited comparisons in this laboratory of the cavitation-erosion resistance in mercury of Kolsterised $\circledast 316 \mathrm{LN}$ specimens with identical 316LN specimens nitrided by collaborators indicated that the former process, as measured by a vibratory horn technique, was 2-3 times more effective in terms of reduced weight loss as a function of sonication time..$^{5,6}$ Subsequently, the technical community associated with the mercury target cavitation issue(s) determined to investigate the potential utility of combining these surface treatments; that is, using the Kolsterisation ${ }^{\circ}$ process followed by plasma nitriding to maximize the cavitation-erosion resistance of $316 \mathrm{LN}$. The purpose of this investigation was to compare/contrast the mercury cavitation-erosion resistance of 
Kolsterised $₫ 316 \mathrm{LN}$ with that of identical specimens that were Kolsterised $\circledast$ and subsequently plasma nitrided. 


\section{EXPERIMENTAL PROCEDURE}

All test specimens were machined from type $316 \mathrm{LN}$ stainless steel with a composition given in Table 1. This is the same heat of $316 \mathrm{LN}$ material that was used in several previous investigations of cavitation-erosion performance in mercury in this laboratory. ${ }^{2-4}$ Specimens were machined from the original cross-rolled plate such that the majority of the few inclusion stringers present were oriented parallel to the test surface. After machining (specimen size/shape details reported previously ${ }^{1}$ and light grinding of the test surface on 800 grit paper, the specimens were vacuum annealed at $1020^{\circ} \mathrm{C}$ at $10^{-4} \mathrm{~Pa}\left(10^{-6}\right.$ torr) or less for $1 \mathrm{~h}$, followed by cooling in the small water-cooled furnace chamber to less than $300^{\circ} \mathrm{C}$ in about $1 \mathrm{~h}$. It is expected that this sequence of treatments generated specimens as free of residual stress - such as associated with the original plate fabrication, machining or grinding of the test surface - as possible.

Table 1. Composition of master heat of $316 \mathrm{LN}$ stainless steel from certified mill report

\begin{tabular}{cccc}
\hline Element & Weight & Element & Weight \% \\
\hline $\mathrm{C}$ & 0.009 & $\mathrm{Cr}$ & 16.31 \\
$\mathrm{Mn}$ & 1.75 & $\mathrm{Ni}$ & 10.20 \\
$\mathrm{P}$ & 0.029 & $\mathrm{Mo}$ & 2.07 \\
$\mathrm{~S}$ & 0.002 & $\mathrm{Co}$ & 0.16 \\
$\mathrm{Si}$ & 0.39 & $\mathrm{Cu}$ & 0.23 \\
$\mathrm{~N}$ & 0.11 & $\mathrm{Fe}$ & balance
\end{tabular}

Following vacuum annealing, six test specimens were subjected to the standard Kolsterising ${ }^{\circledR}$ treatment which was expected to result in a hardened layer nominally

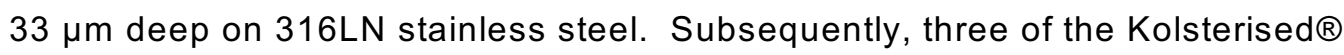
specimens were also subjected to a plasma nitriding process (also performed by the Bodycote Company; details unknown to the author, and not necessarily similar to any nitriding process used by collaborators with the SNS project). The resulting specimens for cavitation testing thereby included three vacuum-annealed buttons with a Kolsterised $₫$ surface and three vacuum-annealed buttons that were Kolsterised $\circledast$ and 
plasma nitrided. Figure 1 is a photograph of the as-received test buttons following each of the test treatments.

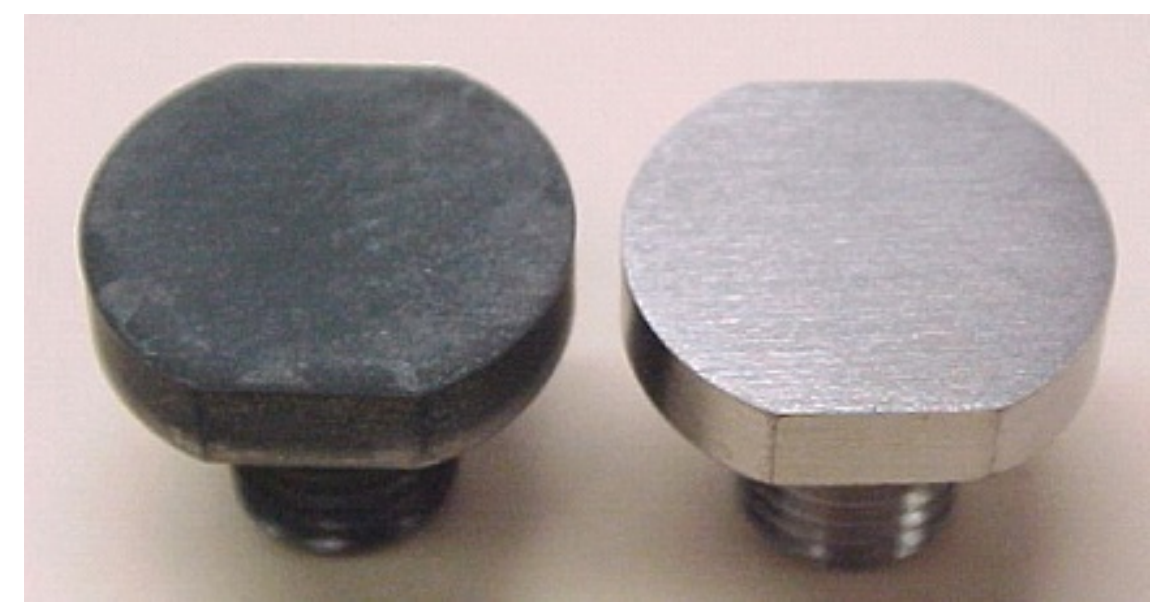

Fig. 1. Appearance of $316 \mathrm{LN}$ cavitation buttons prior to sonication. The darkly colored specimen on the left has received both the Kolsterising $®$ treatment and plasma nitriding, while the otherwise identical specimen on the right has received only the Kolsterising ${ }^{\circledR}$ treatment.

Cavitation-erosion tests were performed using a titanium vibratory horn and the general test methodology described in ASTM G-32. ${ }^{7}$ Each button had a test surface area of $180 \mathrm{~mm}^{2}$ exposed to cavitation conditions and was attached to the horn via a threaded shank. In all cases, the horn tip oscillated at a fixed frequency of $20 \mathrm{kHz}$ and was set to generate a peak-to-peak vibrational amplitude of $25 \mu \mathrm{m}$. All tests were conducted in a jacketed stainless steel container, which permitted temperature control via circulation of a water/glycol mixture from a constant temperature bath. The mercury temperature was monitored in the test bath and was maintained at $25-27^{\circ} \mathrm{C}$ for all tests. The test specimen surface was immersed approximately $2 \mathrm{~mm}$ below the surface of the mercury in the center of the container for all tests. Approximately one liter of high purity mercury was contained within the jacketed vessel and the same mercury was used for all tests. Periodically, cheesecloth was used to skim the mercury surface and remove floating oxides and/or test debris.

Following sonication, test specimens were ultrasonically cleaned sequentially in (1) an aqueous solution containing dissolved thiosulfates and other species to chemically bind 
mercury, (2) distilled water, and (3) acetone, followed by forced air drying in each case. Specimens were then weighed and examined with an optical microscope to assess the average cavitation-erosion surface profile and to evaluate pitting. The profile determination was performed with the calibrated fine focus feature of the optical microscope. Each division on the fine focus knob corresponds to a one-micron vertical movement of the microscope stage, so by sequentially focusing first on the relative high point and then on the low point within a field of view, the depth of surface relief can be estimated. Typically, the average profile was determined from measurements at $400 x$ on seven random but regularly spaced locations across the test surface, with observations of areas of profile significantly different than the average noted as appropriate.

Specimens were also sectioned for metallographic assessment of the profile and microstructural effects at the specimen surface. Post-test specimens were cut and mounted in cross-section to reveal the test surface as well as the specimen edges and threaded region. Standard mounting and polishing techniques were employed and the cross-sections were examined in both the as-polished and etched conditions.

Microhardness scans (Vickers) were made on selected cross-sections in the as-polished condition. The near-surface hardness was determined via diamond indenter with either a 25-g load or a 50-g load, and hardness profiles across any hardened regions were performed by advancing across the surface layer at an angle to permit multiple hardness indentions to be made within very thin surface layers without being too close to an adjacent indentation. While hardness measured in this way may have limited utility in an absolute quantitative sense, the relative hardness across thin layers can be readily compared to the substrate hardness.

To interpret the test results, it is important to recognize that there is no known direct correlation between the damage rate/intensity produced at the tip of the vibratory horn and potential cavitation damage associated with the target vessel of the SNS. The tests performed here simply represent a comparative screening evaluation of the Kolsterising ${ }^{\circledR}$ treatment on $316 \mathrm{LN}$ compared to identical specimens subjected to the Kolsterising ${ }^{\circledR}$ treatment followed by plasma nitriding. 



\section{RESULTS AND DISCUSSION}

In the discussion that follows, specimens with only the Kolsterising ${ }^{\circledR}$ treatment are referred to as "K-layer" specimens. Similarly, specimens receiving the Kolsterising ${ }^{\circledR}$ treatment followed by the plasma nitriding treatment are referred to as " $\mathrm{K}+\mathrm{N}$ layer" specimens.

The weight loss as a function of time for specimens which received the $\mathrm{K}+\mathrm{N}$ treatment is compared to that for specimens which received only the K-layer treatment in Fig. 2. It is apparent that the weight loss rate at extended exposure times is significantly greater for specimens with the $\mathrm{K}+\mathrm{N}$ layer $(3.2 \mathrm{mg} / \mathrm{h})$ than for the $\mathrm{K}$-layer only specimens $(0.8 \mathrm{mg} / \mathrm{h})$, indicating that the cavitation-erosion resistance of Kolsterised $₫ 316 \mathrm{LN}$ is negatively impacted by the nitriding process.

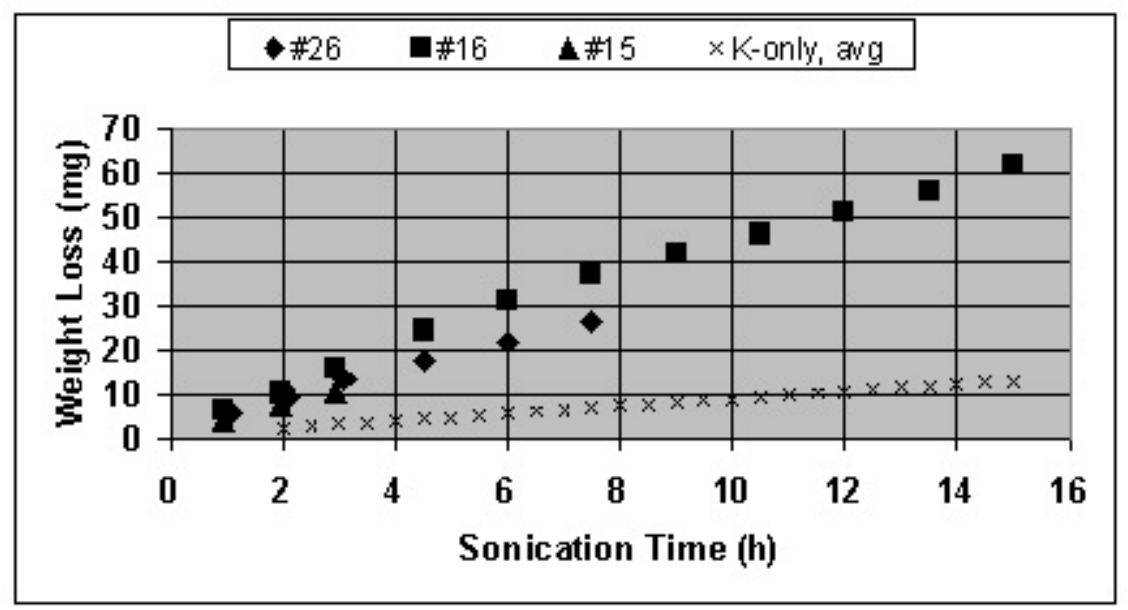

Fig. 2. Weight loss as a function of sonication time in mercury for $316 \mathrm{LN}$ specimens receiving the $\mathrm{K}+\mathrm{N}$ treatment (solid data points representing three different specimens). The data represented by the series of " $x$ " data points represents the average weight loss as a function of time for three identical specimens receiving only the K-layer treatment, for which there is remarkably little scatter/spread in the data.

Figure 3 shows an etched cross-section of the side of a test button which received the $\mathrm{K}+\mathrm{N}$ treatment. Because this region has not been exposed to sonication conditions (it is the side of the specimen rather than the test face) and because the surface layers at this location have the same thickness and appearance on all $\mathrm{K}+\mathrm{N}$ specimens independent of exposure time, it is assumed that the surface layers here are representative of the 
as-treated condition. Light etching of the cross-section revealed the equiaxed austenite grains of the $316 \mathrm{LN}$ base metal appearing in the left half of the photograph. The band of material resulting from Kolsterisation $®$ is labeled "K-layer" in Fig. 3; it appears as a featureless band of relatively uniform thickness (average is 30-35 $\mu \mathrm{m}$ ) contiguous with the base material. The K-layer is austenite identical to the base material except that it is dramatically super-saturated in carbon, which has been shown to significantly harden the treated surface. ${ }^{1}$ The Kolsterisation $®$ process occurs under low temperature conditions which largely prohibits the formation of chromium carbides, and thus none are revealed by the etching process. Further, the general corrosion resistance of the carbide-free austenite is sufficiently improved by carbon impregnation that the affected material is resistant to the mild etchant used to reveal general structure; as a result, even the grain boundary features like those in the base material remain hidden.

Likewise, the band of material resulting from the nitriding process is labeled "N-layer" in Fig. 3; it appears as a generally dark region superimposed on top of the K-layer, and it also exhibits a relatively uniform thickness of 55-60 $\mu \mathrm{m}$. The nitrided layer contains a significant density of chromium nitride precipitates, which are readily etched by the procedure used to develop the structure in Fig. 3.

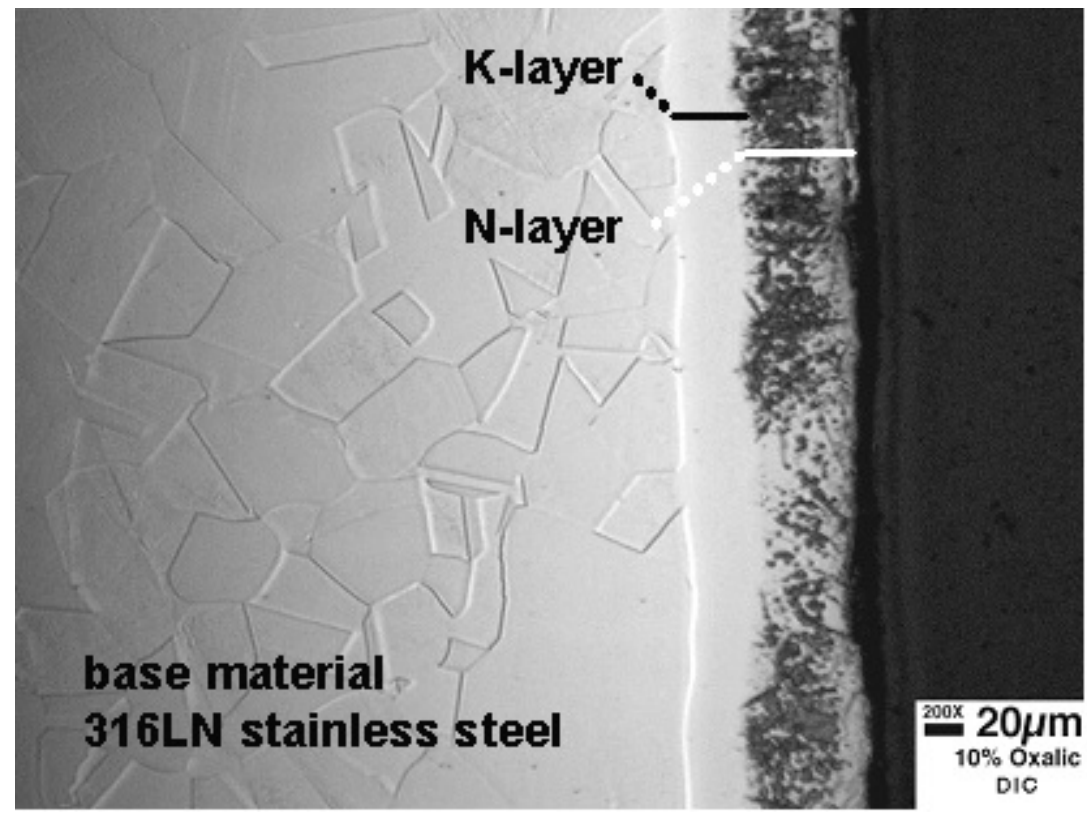

Fig. 3 . Representative cross-section of the side of a test button indicating the thickness and appearance of the as-treated $\mathbf{K}+\mathbf{N}$ layers. The specimen surface is at right (the mounting epoxy is black). 
The nitrided specimens tend to exhibit cracking within the $\mathrm{N}$-layer which, depending on the orientation of the cracks, can generate spalling of this material from the surface. As a general rule, other than limited flake-type shapes at the outermost surface of the $\mathrm{N}$-layer, relatively little cracking was observed on the sides of the $\mathrm{K}+\mathrm{N}$ layer specimens. In Fig. 3, note the flake-like shape of material lifting from the surface at the end of the marker identifying the $\mathrm{N}$-layer band.

Cracks within the $\mathrm{N}$-layer are more readily apparent in the views of Fig. 4, which shows a portion of a threaded segment of a test button in cross section. In the top photograph, the as-polished specimen reveals extensive cracking in the surface layer. The bottom photograph is of exactly the same area but includes etching to reveal the relative position of the $\mathrm{K}$ - and $\mathrm{N}$-layers. Figure 4, which is representative of threaded areas from all specimens with the $\mathrm{K}+\mathrm{N}$ layers, makes it clear that the observed cracking is confined to the $\mathrm{N}$-layer only and does not penetrate into the K-layer. Note that in some locations - near the tip of the thread in this particular case - the cracking is sufficient that most/all of the $\mathrm{N}$-layer had been dislodged from the specimen surface over limited areas. Figure 5 is another example showing that cracking of the $\mathrm{N}$-layer is confined totally within the $\mathrm{N}$-layer; in this particular case, note the large number of short cracks in the residual amount of $\mathrm{N}$-layer on a portion of the thread that all terminate precisely at the K-layer boundary.

It was a common observation that $\mathrm{N}$-layer cracking of the magnitude described above (Figs. 4 and 5) was observed only on the threaded portions of the test specimens, and this may suggest that the mechanical loading on the threads when the specimen is fitted into the vibratory horn are in large measure responsible for this damage. The only other location on which significant spallation of the $\mathrm{N}$-layer was observed was the immediate corners of the test button where the test face meets the sides of the specimen. This observation indicates that high residual stresses within the $\mathrm{N}$-layer may be exacerbated by sharp surface contours on the specimens (near threads and other "corner" shapes). That unusual residual stress patterns reside within the $\mathrm{N}$-layer is evidenced by the photographs in Fig. 6, which again show the threaded portion of a test specimen in cross-section. In this case, note the curved fractures with modest branching which is particularly apparent in the higher magnification photograph. Once again, note that the $\mathrm{N}$-layer cracks may approach, but they do not penetrate, the K-layer boundary. 

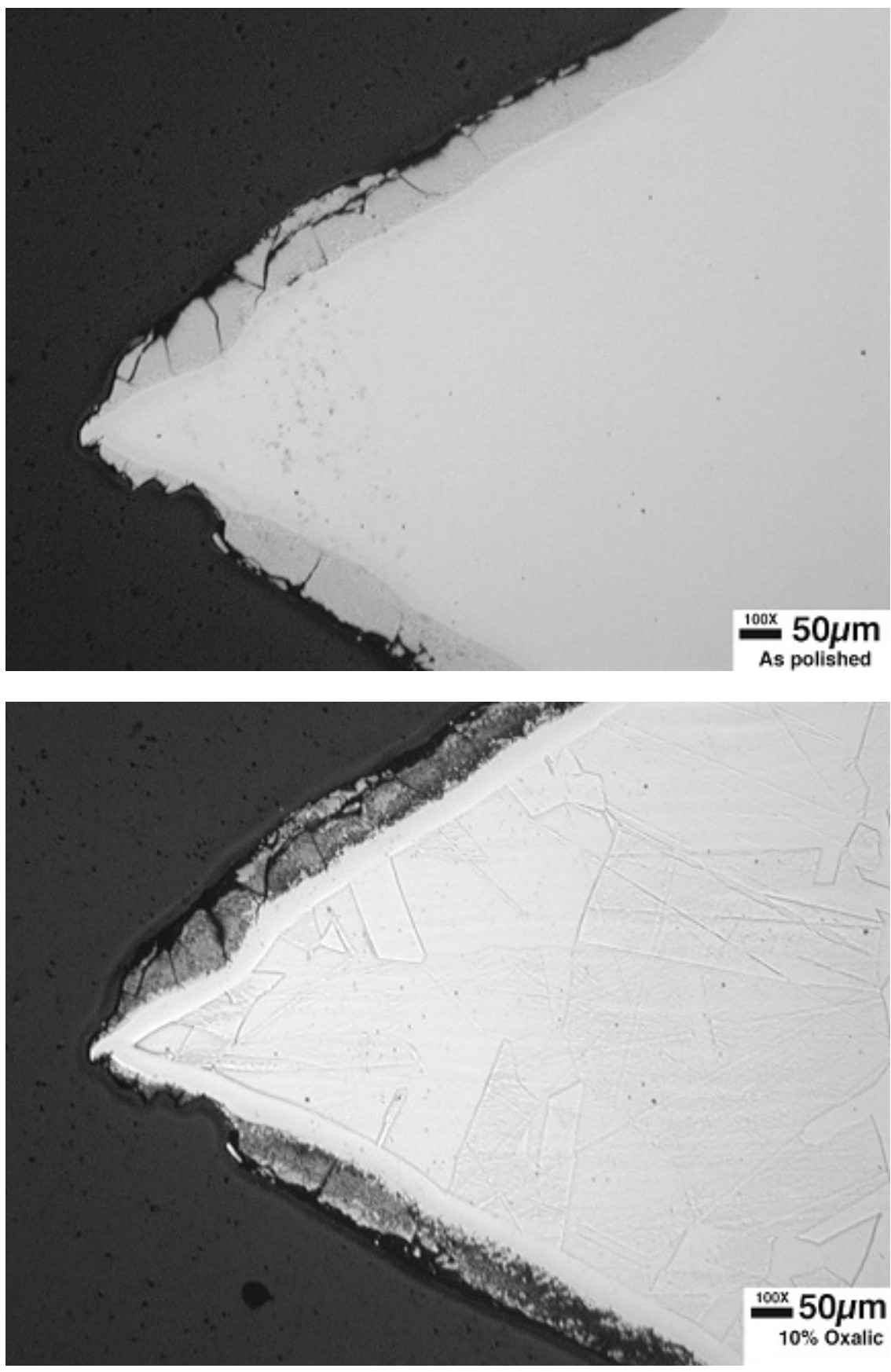

Fig. 4. Cross-section of a threaded portion of a test button showing the same area as-polished (top) and etched

(bottom). This particular thread is from the $\mathrm{K}+\mathrm{N}$ specimen tested for $3 \mathrm{~h}$ prior to sectioning for metallography. In both photographs, the mounting epoxy is black. 


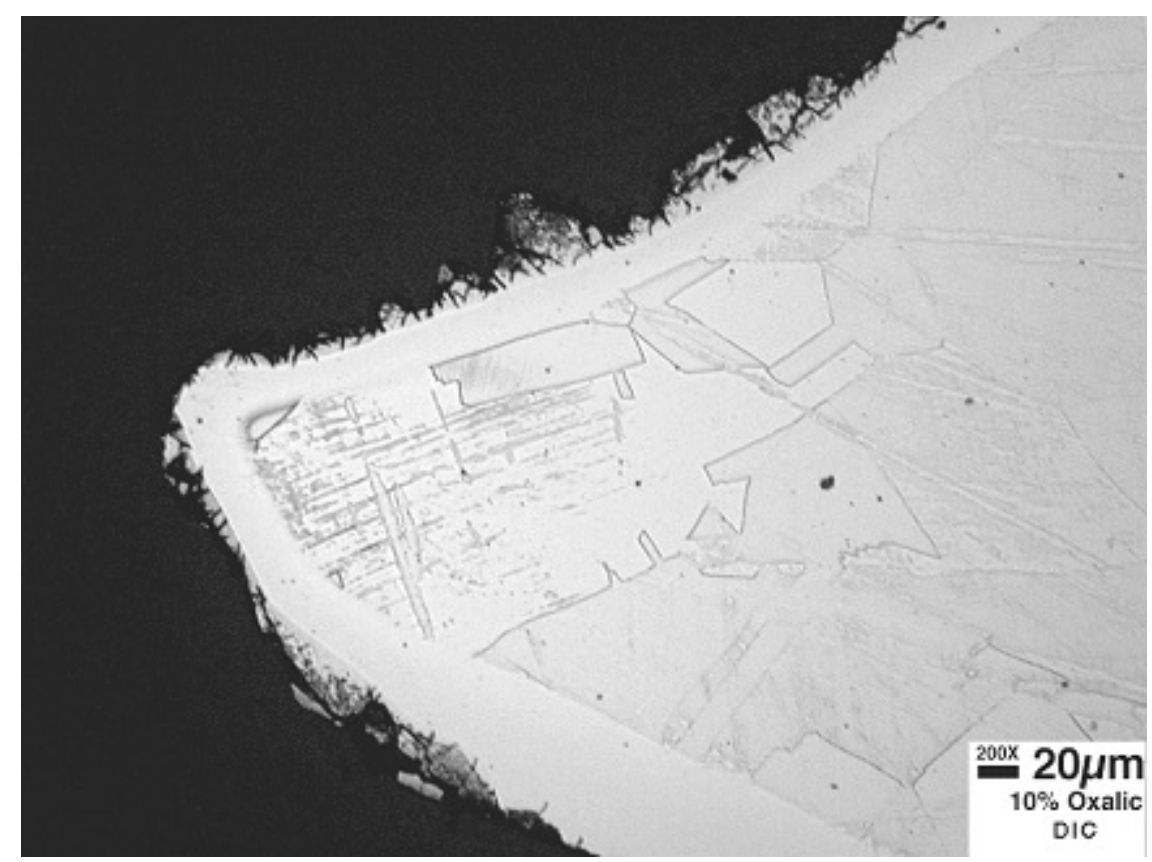

Fig. 5. Cross-section of a specimen thread tip from which most of the $\mathbf{N}$-layer material has spalled. Note particularly along the uppermost portion of the specimen that all the cracks in the residual $\mathrm{N}$-layer terminate precisely at the $\mathrm{K}$-layer boundary. This particular thread is from the $\mathrm{K}+\mathrm{N}$ specimen sonicated for three hours.

Figures 7-9 show representative cross-sections of the test surface of the $\mathrm{K}+\mathrm{N}$ specimens sonicated for 3-, 7.5-, and 15-h, respectively, in mercury at ambient temperature. This series of photographs reveals that the $\mathrm{N}$-layer becomes progressively thinner on the test surface with extended exposure time. However, the N-layer thickness remains constant on the unexposed sides. In all cases, the $\mathrm{N}$-layer exhibits some cracking and/or minor spalling at the various exposure times, but much of this was present in the as-treated condition and remains present on surfaces of the specimen not exposed to sonication conditions (e.g., see Fig. 3). While the $\mathrm{N}$-layer cracking may facilitate some removal of the N-layer on the surface during sonication, it seems unlikely the $\mathrm{N}$-layer cracking is caused by the cavitation-erosion process directly.

Figure 10 shows another location on the cross-section of the $\mathrm{K}+\mathrm{N}$ specimen sonicated for $15 \mathrm{~h}$. In contrast to the comparable views in Fig. 9, which show a continuous but variable-thickness $\mathrm{N}$-layer, Fig. 10 is an example of pit/crater initiation that has compromised essentially the entire $\mathrm{N}$-layer thickness, but not yet penetrated the 
K-layer. Pitting/cratering of this type - generally hemispherical shapes - is the primary mode of material removal from 316LN (and similar alloys) that are not treated to harden the surface, ${ }^{2-4}$ and this type of pitting may signal the onset of failure of the $\mathrm{N}$-layer material.
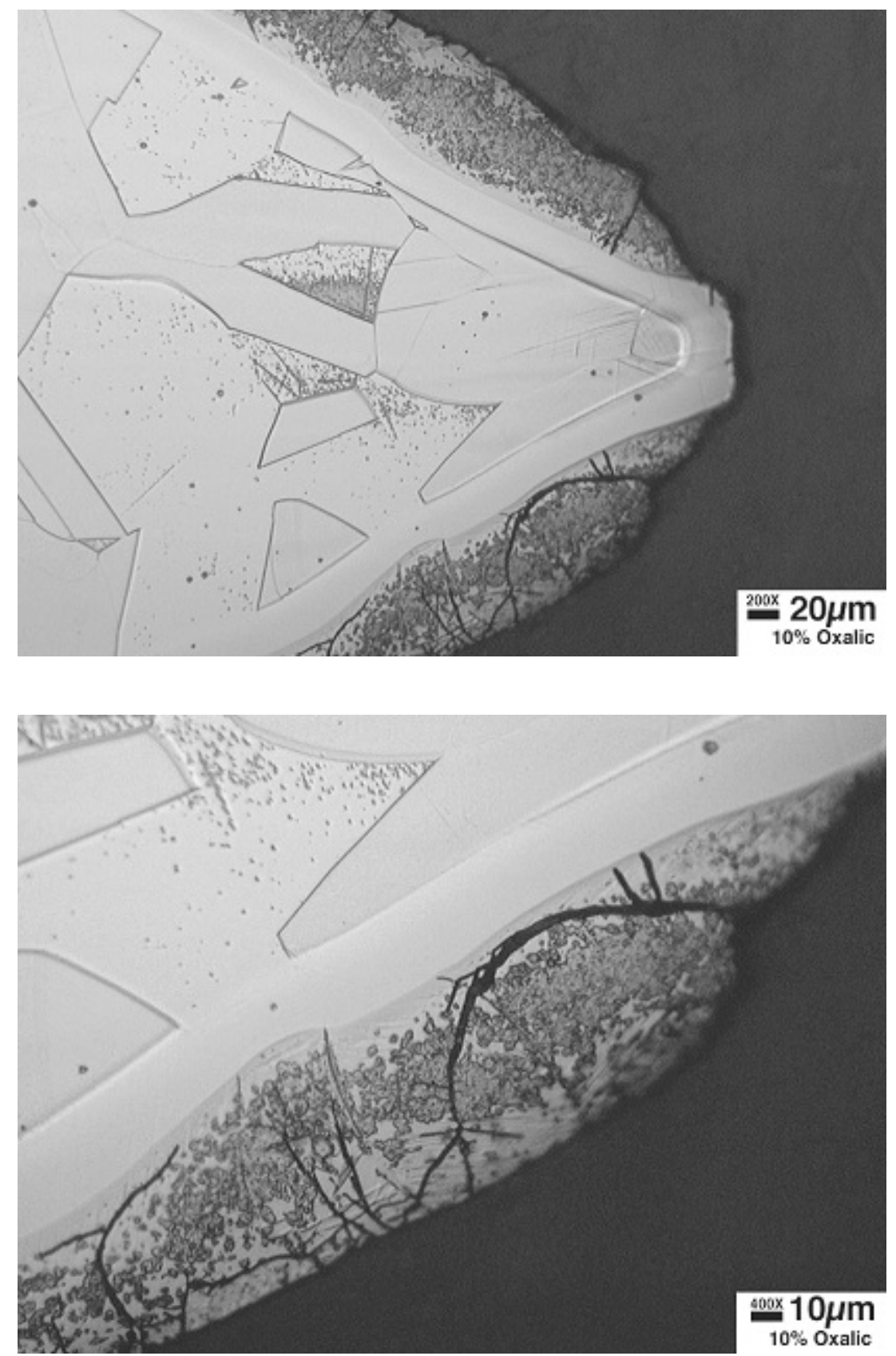

Fig. 6. Cross-section of a specimen thread showing spallation of the $\mathrm{N}$-layer at the tip and curved cracks in the nearby remaining $\mathrm{N}$-layer. This particular thread is from the $\mathrm{K}+\mathrm{N}$ specimen sonicated for $3 \mathrm{~h}$. 

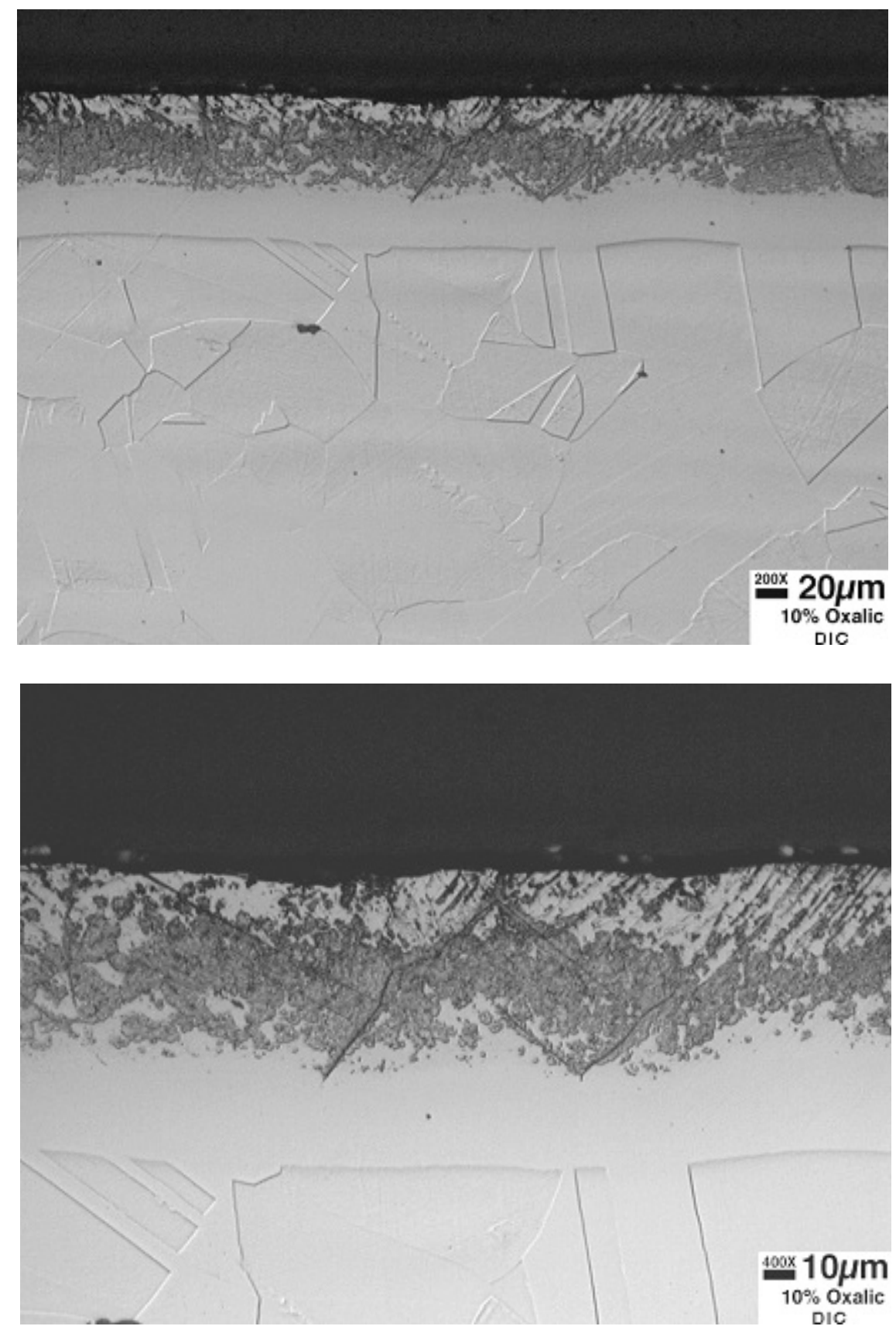

Fig. 7. Cross-section of the test face of a $\mathrm{K}+\mathrm{N}$ specimen sonicated for $\mathbf{3} \mathbf{h}$ in mercury. The average remaining $\mathrm{N}$-layer thickness for this specimen is about $53 \mu \mathrm{m}$. Both photographs are of the same general region, with the lower photograph at higher magnification. The test surface is each case is toward the top of the photograph, and the mounting epoxy appears black. 

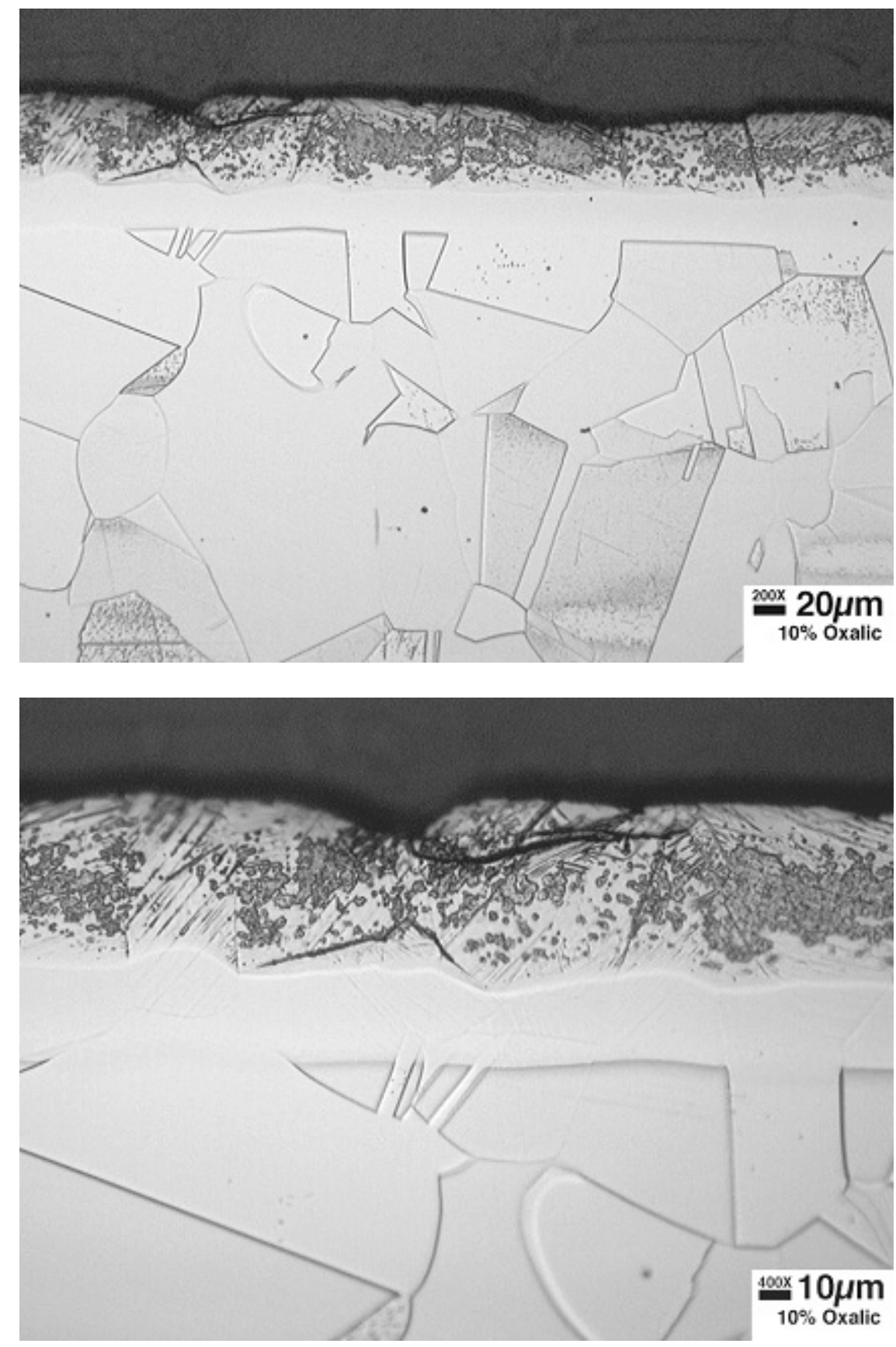

Fig. 8. Cross-section of the test face of a $K+N$ specimen sonicated for $7.5 \mathrm{~h}$ in mercury. The average remaining $\mathrm{N}$-layer thickness for this specimen is about $45 \mu \mathrm{m}$. Both photographs are of the same general region, with the lower photograph at higher magnification. The test surface is each case is toward the top of the photograph, and the mounting epoxy appears black. 

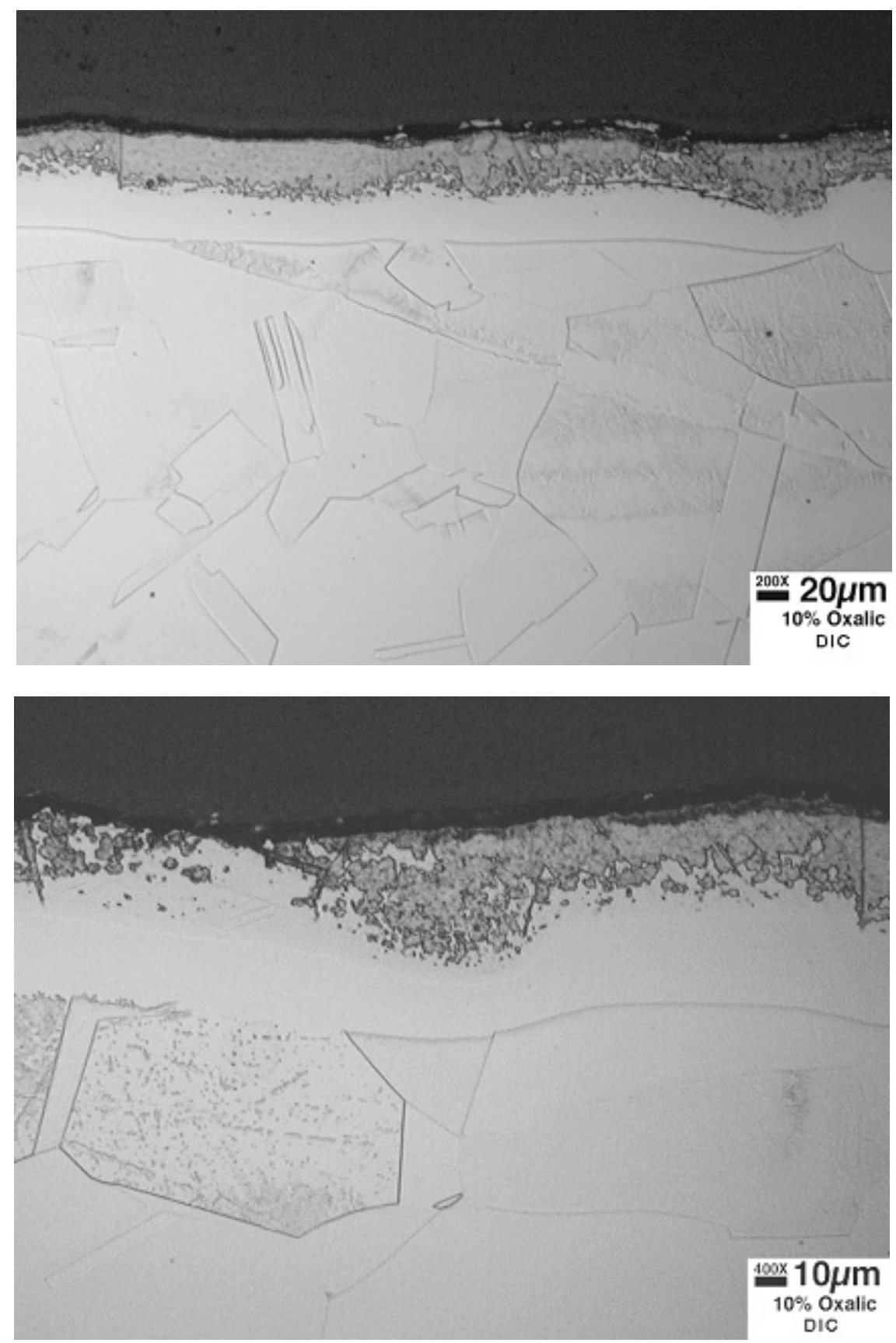

Fig. 9. Cross-section of the test face of a $\mathrm{K}+\mathrm{N}$ specimen sonicated for $\mathbf{1 5} \mathrm{h}$ in mercury. The average remaining $\mathrm{N}$-layer thickness for this specimen is about $30 \mu \mathrm{m}$. Both photographs are of the same general region (linear feature in $\mathrm{N}$-layer is at left in top photo and at right in lower photo), with the lower photograph at higher magnification. The test surface is each case is toward the top of the photograph, and the mounting epoxy appears black. 

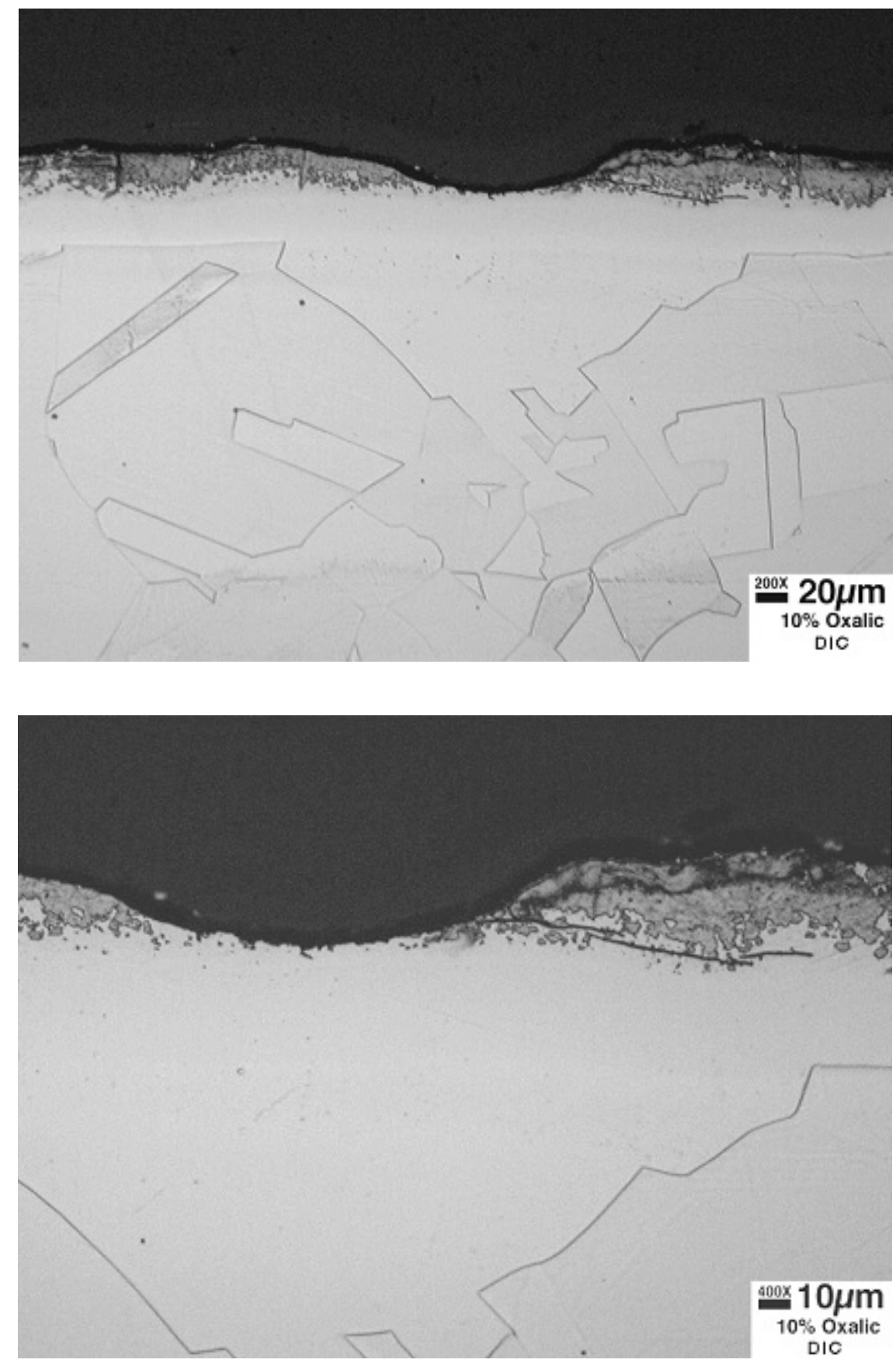

Fig. 10. Cross-section of the test face of a $\mathrm{K}+\mathrm{N}$ specimen sonicated for $\mathbf{1 5} \mathrm{h}$ in mercury. These photographs show representative regions in which the $\mathrm{N}$-layer has been removed/compromised via the sonication process. 
Figure 11 plots the average $\mathrm{N}$-layer thickness (pits not considered) as a function of sonication time. While there is some scatter in the individual data points, it is clear that the general trend can be approximated by a thinning rate of about $2 \mu \mathrm{m} / \mathrm{h}$. Considering a density of $8.0 \mathrm{~g} / \mathrm{cm}^{3}$ for the $316 \mathrm{LN}$ and the layers thereon and $180 \mathrm{~mm}^{2}$ for a total surface area exposed to sonication, a thinning rate of $2 \mu \mathrm{m} / \mathrm{h}$ corresponds to a general weight loss rate of about $2.9 \mathrm{mg} / \mathrm{h}$ for the $\mathrm{K}+\mathrm{N}$ specimens. This compares very favorably with the simple weight loss rate calculated from the data in Fig. $2(3.2 \mathrm{mg} / \mathrm{h})$. [Note: the actual density of the N-layer material is likely to be slightly higher than that for $316 \mathrm{LN}$ due to the added nitrogen (and perhaps carbon, too). Given that the mass loss observed here was entirely within the $\mathrm{N}$-layer, the above estimate to compare weight loss rate with the metallographic thinning result would be somewhat better if the proper density of the N-layer material were used in the calculation. However, neither this precise number nor its change as a function of position in the layer, is known to the author.] Given that mass losses associated with the pitting (thinning to zero on limited areas) of the $\mathrm{N}$-layer at extended exposure time have not been incorporated into this mass loss rate, this comparison suggests the metallography and weight loss measurements agree within some modest scatter. This further indicates that the spallation of the $\mathrm{N}$-layer observed primarily on the threaded regions did not contribute significantly to the observed mass loss, suggesting most of the damage occurs during specimen treatment and subsequent chasing of the threads in preparation for testing.

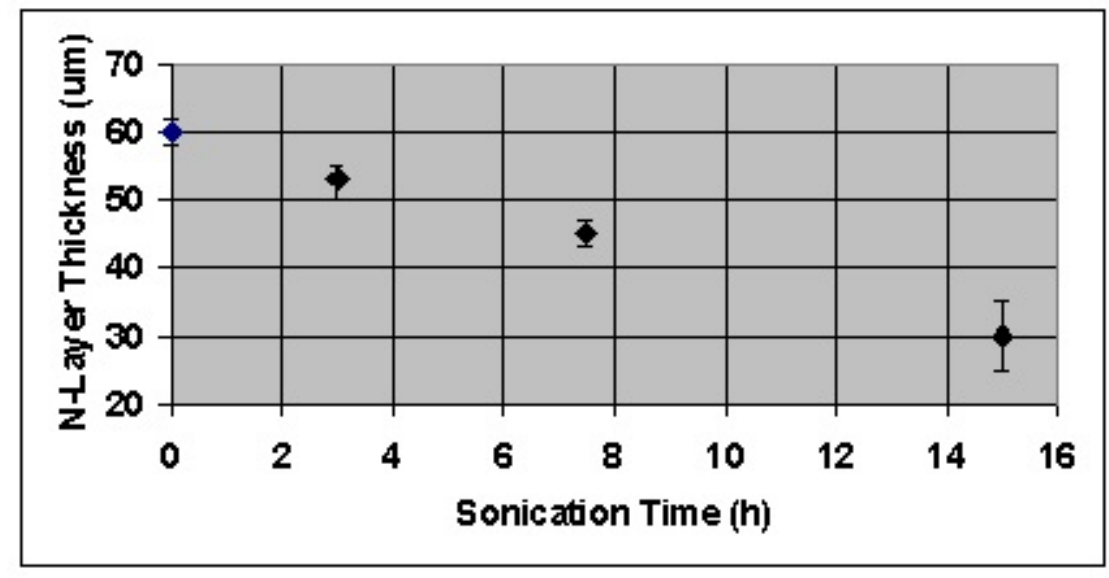

Fig. 11. Remaining N-layer thickness on the test surface as a function of sonication time in mercury at ambient temperature. 
Table 2 contains the average surface profile results obtained for each of the three $\mathrm{K}+\mathrm{N}$ layer specimens in this investigation. These data suggest that the profile increases (surface gets rougher - bigger difference between peaks and valleys) regularly through the initial $7.5 \mathrm{~h}$ or so of sonication. However, further exposure does not increase the average profile an additional amount and instead it decreases slightly before remaining essentially constant. It is possible that the through-thickness properties of the $\mathrm{N}$-layer are such that a change in properties of the $\mathrm{N}$-layer occurs after about $7.5 \mathrm{~h}$ of ablation an example might be a slightly reduced hardness with a corresponding improved toughness/adhesion once the outermost material has been eroded. It may also be that more uniform/general erosion follows $7.5 \mathrm{~h}$ of ablation until the point that pitting (as depicted in Fig. 10) begins to dominate the profile. In any case, since the K-layer seems to remain unattacked even at the bottom of pits that consume the $\mathrm{N}$-layer, the surface profile is necessarily limited by the thickness of the $\mathrm{N}$-layer. Thus, the profile on the $\mathrm{K}+\mathrm{N}$ layer specimens can only continue to decrease until attack initiates on the K-layer. Even after $15 \mathrm{~h}$ sonication time, the specimens receiving only the K-layer treatment have developed very little (not more than isolated examples of $10 \mu \mathrm{m}$ deep) variation in the surface profile. 
Table 2. Average surface profile data for the $\mathrm{K}+\mathrm{N}$ layer specimens compared to the average of all $\mathrm{K}$-layer only specimens

\begin{tabular}{|c|c|c|c|c|}
\hline $\begin{array}{l}\text { Sonication } \\
\text { time, } h\end{array}$ & $\begin{array}{l}\mathrm{K}+\mathrm{N} \text { layer } \\
\text { specimen } \\
\# 26 \text { average } \\
\text { profile, } \mu \mathrm{m}\end{array}$ & $\begin{array}{l}\mathrm{K}+\mathrm{N} \text { layer } \\
\text { specimen } \\
\# 16 \text { average } \\
\text { profile, } \mu \mathrm{m}\end{array}$ & $\begin{array}{l}\mathrm{K}+\mathrm{N} \text { layer } \\
\text { specimen } \\
\# 15 \text { average } \\
\text { profile, } \mu \mathrm{m}\end{array}$ & $\begin{array}{l}\mathrm{K}+\mathrm{N} \text { layer all } \\
\text { specimen } \\
\text { average } \\
\text { profile, } \mu \mathrm{m}\end{array}$ \\
\hline 1 & 13 & 13 & 15 & \\
\hline 2 & 14 & 18 & 19 & 3 \\
\hline 3 & 15 & 22 & 23 & \\
\hline 4.5 & 17 & 24 & & 3 \\
\hline 6 & 23 & 35 & & \\
\hline 7.5 & 26 & 39 & & \\
\hline 9 & & 31 & & \\
\hline 10.5 & & 33 & & \\
\hline 12 & & 33 & & 5 \\
\hline 13.5 & & 31 & & \\
\hline 15 & & 32 & & $<10$ \\
\hline
\end{tabular}

The difference in average surface profile as a function of sonication time is readily apparent on the post-test cavitation buttons, even to the unaided eye. Figure 12 is representative of this result, and it depicts the test surface of a $\mathrm{K}+\mathrm{N}$ layer specimen (\#16) after $4.5 \mathrm{~h}$ sonication compared to a K-layer specimen after $12 \mathrm{~h}$ sonication. Note that the former specimen has an rough/angular, almost grit-blasted looking appearance, with indications of spallation of the $\mathrm{N}$-layer (e.g., front left corner of the specimen) while the latter specimen is very smooth and uniform with only a couple minor pits.

Hardness profiles were performed on the polished cross-sections of test buttons following sonication exposures. Figure 13 is a collection of microhardness data taken from the unexposed sides of several $\mathrm{K}+\mathrm{N}$ layer specimens, and it reveals that the hardness of the $\mathrm{N}$-layer is consistently quite hard (minimum value recorded was $935 \mathrm{DPH}$, or approximately $\mathrm{R}_{\mathrm{c}} 68$ ) but somewhat variable (1194 DPH was the maximum value recorded). Consistent with Fig. 3 , note that the thickness of the $\mathrm{N}$-layer is readily discriminated by relative hardness and is about $55 \mu \mathrm{m}$. The underlying K-layer exhibits 
a steep hardness gradient, with maximum hardness approaching that of the N-layer but decreasing rapidly with increasing depth into the specimen. The hardness of the base metal ( $180 \mathrm{DPH}$, or $\mathrm{R}_{\mathrm{b}} 85$ ) is uniform and generally consistent with typical values for annealed stainless steels.

Microhardness scans taken from exposed test surfaces of $\mathrm{K}+\mathrm{N}$ layer specimens reveal exactly the same type of curve as shown in Fig. 13, except that the apparent thickness of the $\mathrm{N}$-layer is reduced (consistent with the extent of thinning suggested by Fig. 11). Microhardness scans on K-layer only specimens were also performed in this work, but have been more fully documented elsewhere. ${ }^{1}$ The microhardness data measured in cross-section profile tended to yield near-surface hardness (at the outermost reach of the K-layer) about $800 \mathrm{DPH}$ with a rapid decrease across the depth of the carburized layer for both $\mathrm{K}$-layer only specimens as well as $\mathrm{K}+\mathrm{N}$ layer specimens. This result suggests that the plasma nitriding process had little or no effect on the carburized layer. On-face tests ${ }^{1}$ on K-layer only specimens with small loads yielded a surface hardness average of about $1040 \mathrm{DPH}$, suggesting that at the outermost surface, the hardness of the $\mathrm{N}$-layer and the K-layer is about the same. It is clear, however, that the hardness profiles for the two different layers vary considerably from each other. On tests of sufficient duration to ablate a portion of the K-layer, ${ }^{8}$ surface hardness was found to decrease consistent with the thickness change of the K-layer.

Consistent with previous results, ${ }^{2,4}$ the cavitation-erosion data collected here seem to indicate that hardness is not the only measure of merit to define resistance, as the $\mathrm{N}$ layer hardness is equal to (or perhaps slightly greater) than the K-layer hardness, yet the K-layer only surface is significantly more resistant to cavitation-erosion as measured by weight loss and profile development following vibratory horn exposures. Direct comparison of the $\mathrm{N}$-layer performance with that of the $\mathrm{K}$-layer is difficult because the $\mathrm{N}$-layer was applied to a substantially hardened and compositionally modified (enriched with 3-4 wt \% carbon in the near-surface region) $)^{1}$ substrate, while the K-layer was applied to a soft, annealed stainless steel with nominal composition. However, the data gathered here suggest at a minimum that addition of the nitriding layer on a specimen previously carburized with the Kolsterisation $®$ process does not improve the cavitationerosion resistance of $316 \mathrm{LN}$ stainless steel and it perhaps degrades the surface considerably. 

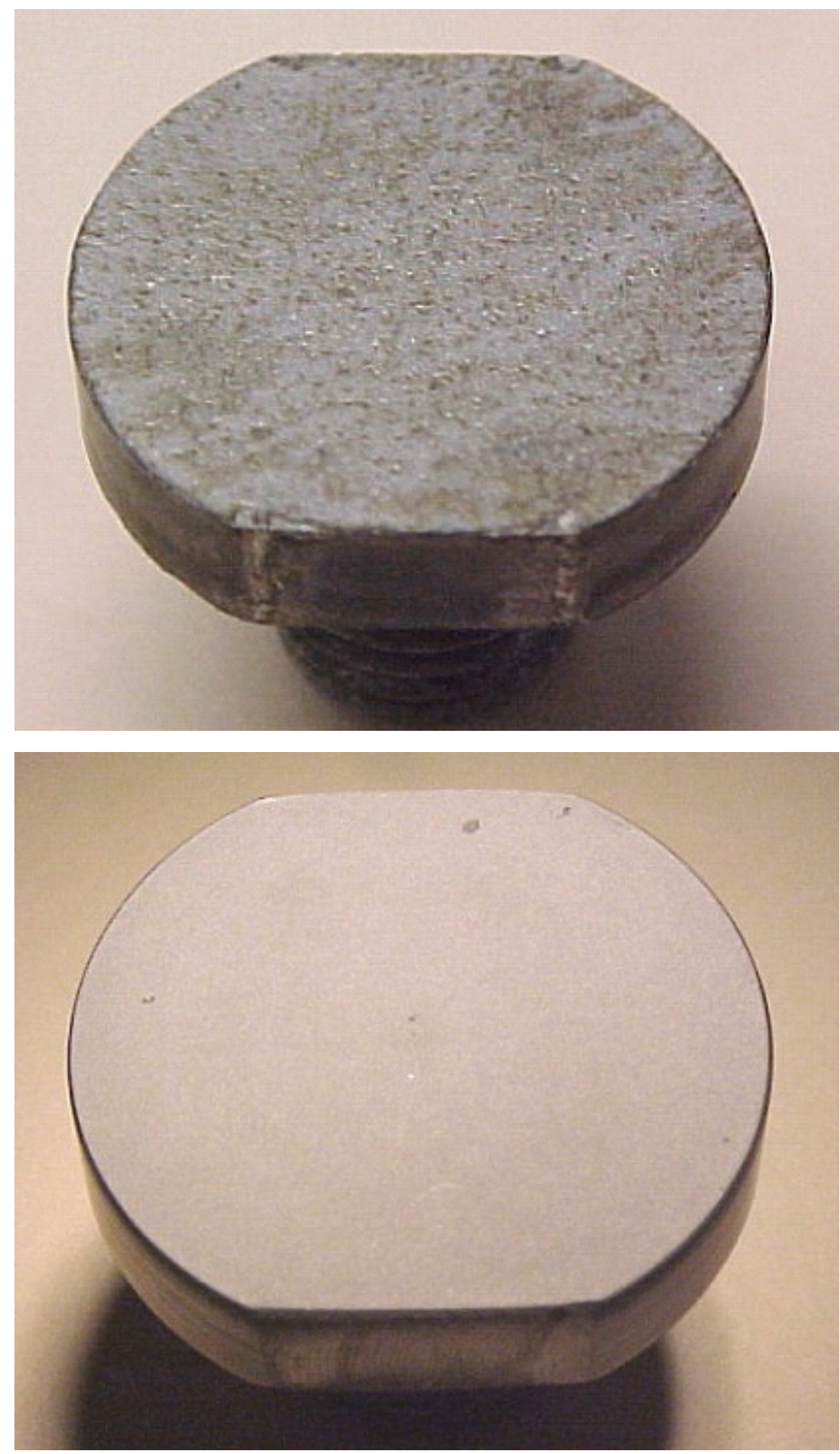

Fig. 12. Comparison of post-test surfaces of assonicated specimens. Top: $\mathrm{K}+\mathrm{N}$ specimen $(\# 16)$ after $4.5 \mathrm{~h}$. Bottom: K-layer specimen after $12 \mathrm{~h}$. Actual diameter of both specimens $=16 \mathrm{~mm}$. 


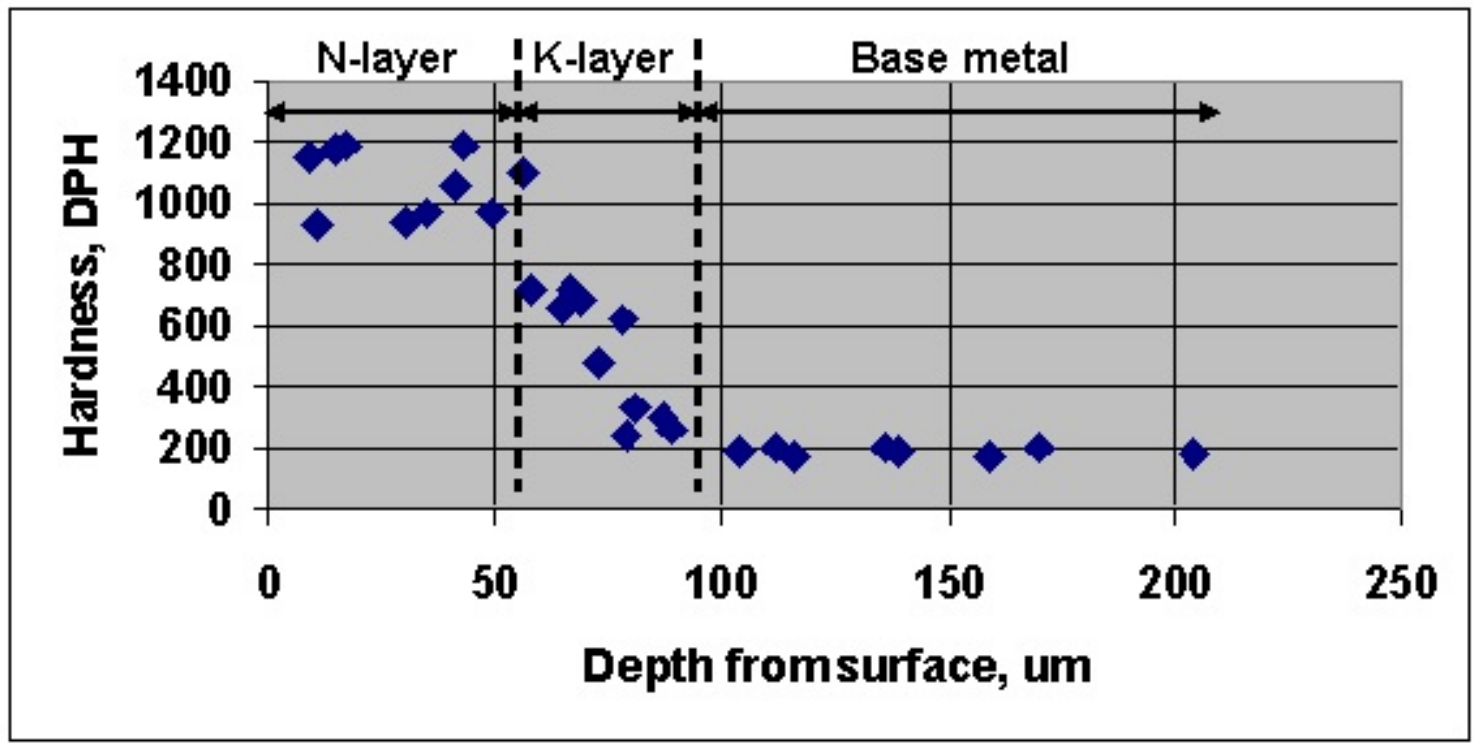

Fig. 13. Microhardness data on $\mathrm{K}+\mathrm{N}$ layer specimens taken on cross sections of sonicated specimens. The data here represent several different scans (25-g load) taken from the unexposed edges of the test buttons. DPH is diamond pyramid hardness. 


\section{CONCLUSIONS}

A vibratory horn test protocol was used to compare and contrast the cavitationerosion resistance in mercury of annealed $316 \mathrm{LN}$ stainless steel specimens that had been either carburized or carburized followed by nitrided. Cavitation-erosion resistance of the carburized surface was degraded by addition of the nitriding process, as evidenced by increased weight loss rate (factor of $\sim 4$ ) and profile development (factor of 3-6) as a function of sonication time. General ablation of the nitrided layer was estimated to occur at about $2 \mu \mathrm{m} / \mathrm{h}$ sonication over the initial $15 \mathrm{~h}$ of testing, while immeasurably small ablation of the carburized layer was observed over the same test period. In addition, numerous cracks were observed in the nitride-rich layer coating; these cracks exhibited variable number densities and lengths, and some were substantially curved (indicating complex residual stress patterns), but none of the nitride-layer cracks was observed to penetrate the carburized layer. 



\section{ACKNOWLEDGMENTS}

The author gratefully acknowledges the contribution of several other individuals to this research and report. Funding for this effort was provided through work managed by B. W. Riemer from the Spallation Neutron Source Project at Oak Ridge National Laboratory, who also arranged for the surface treatments of specimens. H. F. Longmire performed the metallography of the post-test specimens as well as the microhardness evaluations. P. J. Blau and J. R. Keiser reviewed the manuscript. F. C. Stooksbury helped prepare and distribute the manuscript. 



\section{REFERENCES}

1. K. Farrell, et al., "Characterization of a Carburized Surface Layer on an Austenitic Stainless Steel," J. Nucl. Mater., 343 (2005) 123-133.

2. S. J. Pawel and E. T. Manneschmidt, "Preliminary Evaluation of Cavitation Resistance of Type 316LN Stainless Steel in Mercury Using a Vibratory Horn," J. Nucl. Mater., 318 (2003) 122-131.

3. S. J. Pawel, "Assessment of Cavitation-Erosion Resistance of $316 \mathrm{LN}$ Stainless Steel in Mercury as a Function of Surface Treatment," J. Nucl. Mater., 343 (2005) 101-115.

4. S. J. Pawel, Assessment of Cavitation-Erosion Resistance of Potential Pump Impeller Materials for Mercury Service at the Spallation Neutron Source, ORNL/TM-2007/033, March 2007.

5. Internal Memorandum, S. J. Pawel to J. R. Haines and L. K. Mansur, "An Update on Cavitation Testing," January 2, 2004.

6. Internal Memorandum, S. J. Pawel to J. R. Haines, L. K. Mansur, and M. Futakawa, "More Information on Nitrided Specimens," March 10, 2004.

7. Standard Test Method for Cavitation Erosion Using Vibratory Horn Apparatus, ASTM G32-98, American Society for Testing and Materials, Philadelphia, PA, 1998.

8. S. J. Pawel, Assessment of End-of-Life Behavior of the Surface Modification to Improve Cavitation-Erosion Resistance in the Mercury Target at the Spallation Neutron Source, ORNL/TM-2007/063, (in press, expected June 2007). 



\section{INTERNAL DISTRIBUTION}
1. P. J. Blau
2. D. C. Lousteau
3. L. K. Mansur
4. T. J. McManamy
6-8. S. J. Pawel
9. B. A. Pint

\author{
10. B. W. Riemer \\ 11. M. W. Wendel \\ 12. D. F. Wilson \\ 13. S. J. Zinkle \\ 14. Central Research Library \\ 15. ORNL Laboratory Records-RC
}


